\title{
BMJ Open Associations of caesarean delivery and the occurrence of neurodevelopmental disorders, asthma or obesity in childhood based on Taiwan birth cohort study
}

\author{
Ginden Chen, ${ }^{1,2,3}$ Wan-Lin Chiang, ${ }^{1}$ Bih-Ching Shu, ${ }^{4}$ Yue Leon Guo, ${ }^{5}$ \\ Shu-Ti Chiou, ${ }^{6}$ Tung-liang Chiang ${ }^{1}$
}

To cite: Chen G, Chiang W-L, Shu B-C, et al. Associations of caesarean delivery and the occurrence of neurodevelopmental disorders, asthma or obesity in childhood based on Taiwan birth cohort study. BMJ Open 2017;7:e017086. doi:10.1136/ bmjopen-2017-017086

- Prepublication history for this paper is available online. To view these files, please visit the journal online (http://dx.doi. org/10.1136/bmjopen-2017017086).

Received 30 March 2017 Revised 18 August 2017 Accepted 6 September 2017

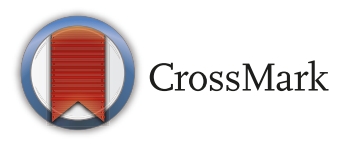

For numbered affiliations see end of article.

Correspondence to Professor Tung-liang Chiang; tlchiang@ntu.edu.tw

\section{ABSTRACT}

Objectives Whether birth by caesarean section (CS) increases the occurrence of neurodevelopmental disorders, asthma or obesity in childhood is controversial. We tried to demonstrate the association between children born by CS and the occurrence of the above three diseases at the age of 5.5 years.

Methods The database of the Taiwan Birth Cohort Study which was designed to assess the developmental trajectories of 24200 children born in 2005 was used in this study. Associations between children born by CS and these three diseases were evaluated before and after controlling for gestational age (GA) at birth, children's characteristics and disease-related predisposing factors. Results Children born by CS had significant increases in neurodevelopmental disorders (20\%), asthma (14\%) and obesity (18\%) compared with children born by vaginal delivery. The association between neurodevelopmental disorders and CS was attenuated after controlling for GA at birth (OR 1.15; $95 \% \mathrm{Cl} 0.98$ to 1.34). Occurrence of neurodevelopmental disorders steadily declined with increasing GA up to $\leq 40-42$ weeks. CS and childhood asthma were not significantly associated after controlling for parental history of asthma and GA at birth. Obesity in childhood remained significantly associated with CS (OR $1.13 ; 95 \% \mathrm{Cl} 1.04$ to 1.24 ) after controlling for $\mathrm{GA}$ and disease-related factors.

Conclusions Our results implied that the association between CS birth and children's neurodevelopmental disorders was significantly influenced by GA. CS birth was weakly associated with childhood asthma since parental asthma and preterm births are stronger predisposing factors. The association between CS birth and childhood obesity was robust after controlling for disease-related factors.

\section{INTRODUCTION}

With an escalating rate of caesarean sections (CS) worldwide, literature has revealed that caesarean delivery might delay neurological adaptation in infants and can also alter gut microbiotic composition in early

\section{Strengths and limitations of this study}

- Our database simultaneously demonstrates whether neurodevelopmental disorders, asthma and obesity are associated with modes of delivery after controlling for potential confounding factors.

- We evaluated dose-dependent effects of gestational age on the occurrence of these diseases.

- Some information such as maternal/fetal conditions that indicate CS or precise indications of CS that might be more related to these disorders were not evaluated because indications for CS were derived from self-reports by mothers or reports by primary caregivers, not from medical records.

- We might have missed the possibility that these disorders might occur in combination because we looked at associations among these three disorders and modes of delivery as mutually exclusive.

infancy. ${ }^{1}$ Recent studies demonstrate that different delivery modes shape the diversity in the human microbiome's successional development in different body habitats and might alter gut the microbiotic composition which probably has associated effects on infant health. ${ }^{3}$ However, whether modes of delivery also result in long-term physiological consequences in childhood or influence later physical well-being needs further investigation.

Kapellou pointed out that the delivery of infants before 39 weeks can increase respiratory morbidity and interrupt intrauterine brain maturation and have a significant impact on future neurodevelopment. ${ }^{4}$ Animal studies have shown that CS may affect development of neurons and that some fetal brain developmental processes continue into the neonatal period. ${ }^{56}$ In the past, mode of delivery has been shown to potentially affect normal intestinal colonisation in infants 
as demonstrated by checking faecal flora. ${ }^{7}$ Collins et al revealed that intestinal microbiota could communicate with the brain via the gut-brain axis to influence brain development and behaviour. ${ }^{8}$ However, the correlation between CS and later neurodevelopmental disorders is still controversial.

Overweight children and increase of allergic diseases have been reported to be associated with CS delivery based on the hygiene hypothesis. ${ }^{9-13}$ A meta-analysis demonstrated a $20 \%$ increase in the subsequent risk of asthma in children who had been delivered by CS. ${ }^{9}$ A population-based cohort study found a moderately increased risk of asthma in the children delivered by CS and also found that this association was stronger for preterm children than for term children. ${ }^{14}$ However, some longitudinal studies show no associations between subsequent risk of developing childhood asthma, wheezing episodes or atopic dermatitis in infants delivered by CS after controlling for their parental allergy history. ${ }^{15}{ }^{16}$ Epidemiological studies also revealed an association between $\mathrm{CS}$ and overweight or obese preschool-aged children. ${ }^{10} 11$ Recently, a systematic review and meta-analysis indicated that CS is only moderately associated with overweight and obese children. ${ }^{17}$ The inconsistent association between delivery modes and childhood allergies as well as overweight/obesity also needs clarification by further study.

In this study, we used data from the Taiwan Birth Cohort Study (TBCS) to demonstrate whether neurodevelopmental disorders, asthma and obesity at the age of 5.5 years are associated with modes of delivery after controlling for potential confounding factors. Except for the basic demographic factors of children and socioeconomic status of parents, the potential confounding factors also include specific factors that might be related to the occurrence of neurodevelopmental disorders, asthma and obesity.

\section{MATERIALS AND METHODS}

\section{Study population and setting}

Data used in this study were derived from the TBCS. The TBCS has been designed to assess the developmental trajectories of Taiwanese children and was financially sponsored by the Health Promotion Administration in Taiwan. The study protocol and questionnaires were approved by the Directorate-General of Budget, Accounting and Statistics in the Executive Yuan, according to the Statistics Act of Taiwan. This study was approved by the Institutional Review Board at the National Taiwan University Hospital (No. 201604055RINC).

By using two-stage stratified random sampling, the TBCS selected a nationally representative sample of 24200 children born in 2005 from the National Birth Report Database, with a sampling rate of approximately $11.7 \%$. Before children reached school age, face-to-face survey interviews with mothers or primary caregivers were conducted at 6 months, 18 months, 36 months and 5.5 years of age, with response rates of $87.8 \%, 94.9 \%, 93.7 \%$ and $92.8 \%$, respectively. Our study sample included 19721 children who participated the first and fourth surveys. The content of both surveys contains questions about the child's developmental, behavioural and health outcomes, as well as detailed information on family characteristics including socioeconomic conditions, parenting practices and the parents' health and well-being.

\section{Children's health status, modes of delivery and gestational age}

In this study, we focused on childhood obesity, asthma and neurodevelopmental disorders. Childhood obesity was defined by the body mass index set by the Taiwan Bureau of Health Promotion for preschool children. Children categorised with asthma were those who had been diagnosed by a physician as described by Wen et $a l .{ }^{18}$ Learning disabilities, developmental delay, attention deficit hyperactivity disorder, sensory integration disorder and autism were diagnosed and evaluated by paediatric psychiatrists and clinical psychologists. Children with neurodevelopmental disorders were categorised as those having any or a combination of learning disabilities, developmental delay, attention deficit hyperactivity disorder, sensory integration disorder or autism, according to the classification of the Diagnostic and Statistical Manual of Mental Disorders Fifth Edition (DSM-V) published on 27 May $2013 .^{19}$

Information about the mode of delivery (vaginal or caesarean delivery) and gestational age (GA) was also collected from Taiwanese birth certificates in 2005. GA was stratified as: preterm ( $<37$ weeks), term ( 37 to 41 weeks) and post-term (42 weeks or more). To evaluate the influence of GA on the associations of CS with the occurrence of the above three diseases, we further divided term pregnancy into 37 weeks, 38 weeks, 39 weeks and 40-41 weeks for comparison.

\section{Parental characteristics used as control variables}

Mothers' educational levels were classified as compulsory school (less than 9 years of schooling), senior high school, junior college, college and above. Household monthly income was categorised as less than NT\$30 000, NT\$30000-100000 and more than NT\$100 000 (NT\$30=US\$1). Gestational weight gain among the mothers was grouped as less than $11 \mathrm{~kg}$ and $11 \mathrm{~kg}$ or more. The occurrence of gestational diabetes diagnosed during prenatal care visits was also recorded. Parental history of asthma was recorded at the first survey.

\section{Statistical analysis}

Children's characteristics, obesity, asthma and neurodevelopmental disorders were compared with $\chi^{2}$ tests. Logistic multiple regression analyses were used to evaluate obesity, asthma and neurodevelopmental disorders associated with CS after controlling for characteristics of children (ie, GA, gender, birth order) and parents (ie, mother's age at birth of child, mother's education levels, family monthly income). We also included 
disease-specific factors such as parental asthma history for children's asthma, gestational diabetes mellitus and gestational weight gain of mother for children's obesity as controlling factors to demonstrate their effects on these disorders. The Cochran-Armitage Trend Test was used to check dose-dependent effects on the occurrence of these three diseases across the preterm, early term period of $37-40$ weeks (GA at 37 weeks $-<38$ weeks, 38 weeks $-<39$ weeks, 39 weeks $-<40$ weeks) and $\geqq 40$ weeks. Alpha level was set as 0.05 . All statistical analyses were performed using the Statistical Analysis Software package, SAS V.9.3.

\section{RESULTS}

In total, data of 19721 children (cohort CS rate: 33.2\%) were successfully collected: neurodevelopmental disorders 19 717, asthma 19720 and obesity, 19269. The children's and parental characteristics are shown in table 1. The prevalence of children's neurodevelopmental disorders, asthma and obesity were significantly different between birth by CS and vaginal delivery $(4.7 \%$ vs $3.8 \%$, $7.3 \%$ vs $6.3 \%, 15.9 \%$ vs $14.0 \%$; respectively, all $\mathrm{p}<0.05)$.

\section{Association between neurodevelopmental disorders and CS delivery}

Table 2 shows predisposing factors that might influence an association between neurodevelopmental disorders and birth by CS. The OR and 95\% CI for caesarean delivery were 1.22 and 1.05-1.42 after controlling for children's and parental characteristics. Gender was significantly associated with children's neurodevelopmental disorders (OR for male: 2.16). A young maternal age at childbirth was found to be a protective factor against neurodevelopmental disorders in the children. Monthly household income had an inverse association with the occurrence of children's neurodevelopmental disorders.

The association between neurodevelopmental disorders and birth by CS was attenuated after controlling for GA in a regression model (OR 1.15; 95\% CI 0.98 to 1.34 ). Children born by CS at a GA of less than 38 weeks were significantly associated with more neurodevelopmental disorders (GA less than 37 weeks: OR 1.94; 95\% CI 1.55 to 2.42; GA at 37 weeks: OR 1.24; $95 \%$ CI 1.0 to 1.55 ; all $\mathrm{p}<0.05)$

\section{Association between asthma and CS delivery}

Table 3 shows that asthma was associated with birth by CS (OR 1.16; 95\% CI 1.03 to 1.30) after controlling for children's and parental characteristics. Gender and first-born children had a significant association with childhood asthma (ORs for males and first-born child: 1.40 and 1.23). A lower maternal educational level was a protective factor against childhood asthma. Children born in families with a lower monthly income had fewer occurrences of asthma.

The association between asthma and children born by CS was attenuated after controlling for GA (OR 1.11; $95 \%$ CI 0.98 to 1.25$)$. Children born at a GA of less than
37 weeks (OR 1.27; $95 \%$ CI 1.03 to 1.56 ) had a significant association with more asthma. CS and childhood asthma were not significantly associated after further controlling parental history of asthma. However, children born at a GA of less than 37 weeks, at 38 weeks, boys, first-born children and mother's educational level were still associated with more asthma. Parental history of asthma was more significantly associated with childhood asthma (OR 3.62; $95 \%$ CI 2.88 to 4.55 ).

\section{Association between childhood obesity and CS delivery}

Table 4 shows that childhood obesity was associated with birth by CS (OR 1.15; 95\% CI 1.06 to 1.26) after controlling for children's and parental characteristics. Gender, first-born children and lower maternal education level were predisposing factors for childhood obesity. We found that obesity in childhood remained significantly associated with caesarean delivery (OR 1.15; 95\% CI 1.05 to 1.25) after controlling for GA. Children born postterm had a significant association with childhood obesity. Male gender, first-born child and lower maternal educational level were also associated with obesity in childhood. Furthermore, birth by CS and childhood obesity were still associated when we included gestational diabetes (OR 1.53; 95\% CI 1.20 to 1.95) and maternal gestational weight gain ( $\geqq 11 \mathrm{~kg}$; OR 1.18 ; $95 \%$ CI 1.07 to 1.30 ) as control variables.

\section{Dose effect of GA on these three disorders}

Further, we found that there was an association between CS at a GA of less than 37 weeks and neurodevelopmental disorders with a dose effect of GA until term. The association of premature birth and neurodevelopmental disorders also existed in the regression analysis while excluding the children born by primary CS due to mandatory medical factors. The risk of occurrence of neurodevelopmental disorders steadily declined with increasing GA up to $39-<2$ weeks (data not shown). However, there was no dose effect of the GA until term on childhood asthma and obesity.

\section{DISCUSSION}

In this study, children born by CS had significant increases in neurodevelopmental disorders (20\%), asthma (14\%) and obesity (18\%) compared with children born by vaginal delivery. However, except for obesity, associations between CS births and children's neurodevelopmental disorders or asthma were attenuated after controlling for GA and potential disease-related predisposing factors.

\section{Effect of GA on these three disorders}

Our results are consistent with the findings of MacKay et $a .^{20}{ }^{20}$ We found that the risk of occurrence of neurodevelopmental disorders was significantly associated with a GA of less than 37 weeks and steadily declined with increasing GA up to $\leq 40-<42$ weeks and with a dose effect of the gestation until term. These results support 
Table 1 Characteristics of cohort members by child health at 5 years (sample 19721 )

\begin{tabular}{|c|c|c|c|c|}
\hline & Total, n (\%) & $\begin{array}{l}\text { Vaginal delivery, } \\
\text { n (\%) }\end{array}$ & $\begin{array}{l}\text { Caesarean delivery, } \\
\text { n (\%) }\end{array}$ & \\
\hline Total & $19721(100.0)$ & $13143(66.6)$ & $6556(33.2)$ & \\
\hline Neurodevelopmental disorders & $804(4.1)$ & $497(3.8)$ & $307(4.7)$ & $\star \star \star$ \\
\hline Learning disabilities & $290(1.5)$ & $179(1.4)$ & $111(1.7)$ & \\
\hline Developmental delay & $525(2.7)$ & $322(2.5)$ & $203(3.1)$ & ** \\
\hline ADHD & $183(0.9)$ & $112(0.9)$ & $71(1.1)$ & \\
\hline Sensory integration disorder & $254(1.3)$ & $147(1.1)$ & $107(1.6)$ & ** \\
\hline Autism & $88(0.4)$ & $52(0.4)$ & $36(0.5)$ & \\
\hline Asthma & $1311(6.7)$ & $831(6.3)$ & $478(7.3)$ & * \\
\hline Obesity & $2896(14.7)$ & $1844(14.0)$ & $1046(15.9)$ & *** \\
\hline \multicolumn{5}{|l|}{ Gender } \\
\hline Male & $10358(52.6)$ & $6785(51.6)$ & $3561(54.3)$ & $* \star \star$ \\
\hline \multicolumn{5}{|l|}{ Birth order } \\
\hline First-born child & $9918(50.4)$ & $6833(52.0)$ & $3085(47.1)$ & *** \\
\hline Gestational age, weeks & & & & *** \\
\hline$<37$ & $1644(8.3)$ & $784(6.0)$ & $857(13.1)$ & \\
\hline 37 & $2557(13.0)$ & $1348(10.3)$ & $1206(18.4)$ & \\
\hline 38 & $5282(26.8)$ & $3124(23.8)$ & $2152(32.8)$ & \\
\hline 39 & $5601(28.4)$ & $4250(32.3)$ & $1343(20.5)$ & \\
\hline $40-41$ & $4580(23.2)$ & $3603(27.4)$ & $975(14.9)$ & \\
\hline$\geqq 42$ & $57(0.3)$ & $34(0.3)$ & $23(0.4)$ & \\
\hline Maternal age at birth of child, years & & & & *** \\
\hline$<25$ & $2882(14.6)$ & $2288(17.4)$ & $591(9.0)$ & \\
\hline $25-29$ & $6401(32.5)$ & $4514(34.3)$ & $1880(28.7)$ & \\
\hline $30-34$ & $7032(35.7)$ & $4522(34.4)$ & $2503(38.2)$ & \\
\hline$\geqq 35$ & 3406 (17.3) & $1819(13.8)$ & $1582(24.1)$ & \\
\hline Maternal education level & & & & 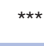 \\
\hline Compulsory school & $2846(14.5)$ & $2061(15.7)$ & $780(11.9)$ & \\
\hline Senior high school & 7908 (40.2) & $5147(39.2)$ & $2756(42.1)$ & \\
\hline Junior college & 4959 (25.2) & $3277(25.0)$ & $1675(25.6)$ & \\
\hline College and above & $3974(20.2)$ & $2636(20.1)$ & $1333(20.4)$ & \\
\hline Family monthly income & & & & *** \\
\hline$<30000$ & $2745(14.1)$ & $1860(14.3)$ & $881(13.5)$ & \\
\hline $30000-100000$ & $13729(70.3)$ & $9211(70.8)$ & 4502 (69.2) & \\
\hline$>100000$ & 3065 (15.7) & $1944(14.9)$ & $1119(17.2)$ & \\
\hline Parental asthma history & $518(2.6)$ & $328(2.5)$ & $190(2.9)$ & \\
\hline Gestational diabetes mellitus & $435(2.2)$ & $200(1.5)$ & $234(3.6)$ & $\star * \star$ \\
\hline Gestational weight gain, kg & & & & *** \\
\hline$<11$ & $4766(24.4)$ & 3309 (25.4) & $1449(22.3)$ & \\
\hline $11-13$ & $4697(24.0)$ & $3306(25.4)$ & $1385(21.3)$ & \\
\hline $14-16$ & $4631(23.7)$ & $3138(24.1)$ & $1491(22.9)$ & \\
\hline$\geqq 17$ & $5448(27.9)$ & $3272(25.1)$ & $2171(33.4)$ & \\
\hline
\end{tabular}

Missing data in modes of delivery: $0.2 \%$; birth order: $0.2 \%$; gestational age: $0.1 \%$; maternal age at birth of child: $0.1 \%$; maternal educational levels: $0.3 \%$ and family monthly income: $1.0 \%$; parental asthma history: $0.5 \%$; gestational diabetes mellitus: $0.2 \%$; gestational weight gain: $0.9 \%$. Number of mothers or main caregivers who completed the questions regarding the three children's health issues: neurodevelopmental disorders: 19717 ; asthma: 19720 and obesity: 19269. Data of modes of delivery from birth registration.

$\chi^{2}$ for analysing differences of obesity, asthma, neurodevelopmental disorders, gender and birth order between vaginal and caesarean delivery. ${ }^{*} \mathrm{p}<0.05 ;{ }^{* *} \mathrm{p}<0.01 ;{ }^{* \star *} \mathrm{p}<0.001$.

the hypothesis proposed by Kapellou which implies that the fetal brain develops and matures towards the end of gestation. ${ }^{4}$ Our results also seem to indirectly provide data to support that neurodevelopmental outcomes are affected by premature interruption of intrauterine life. $^{21} 22$ 
Table 2 Association between caesarean delivery and the occurrence of children's neurodevelopmental disorders after controlling for gestational age, children's and parental characteristics

\begin{tabular}{|c|c|c|c|c|}
\hline & Adjusted OR & $95 \% \mathrm{Cl}$ & Adjusted OR & $95 \% \mathrm{Cl}$ \\
\hline Caesarean delivery & 1.22 & 1.05 to 1.42 & 1.15 & 0.98 to 1.34 \\
\hline \multicolumn{5}{|l|}{ Gestational age (reference: 39-41 weeks) } \\
\hline 37 weeks & & & 1.24 & 1.00 to 1.55 \\
\hline 38 weeks & & & 0.97 & 0.81 to 1.17 \\
\hline Gender, male (reference: female) & 2.16 & 1.85 to 2.52 & 2.13 & 1.83 to 2.49 \\
\hline First-born child (reference: not first-born child) & 1.13 & 0.97 to 1.31 & 1.17 & 1.00 to 1.36 \\
\hline \multicolumn{5}{|c|}{ Maternal age at birth of child (reference: $\geqq 35$ years) } \\
\hline$<25$ years & 0.75 & 0.58 to 0.98 & 0.76 & 0.58 to 1.00 \\
\hline$\leq$ Compulsory school & 1.09 & 0.82 to 1.44 & 1.07 & 0.81 to 1.41 \\
\hline Senior high school & 0.97 & 0.78 to 1.22 & 0.97 & 0.77 to 1.21 \\
\hline Junior college & 0.96 & 0.76 to 1.21 & 0.96 & 0.76 to 1.21 \\
\hline \multicolumn{5}{|l|}{ Family monthly income (NTD) (reference: >100000) } \\
\hline$<30000$ & 2.23 & 1.66 to 3.00 & 2.23 & 1.66 to 3.00 \\
\hline $30000-100000$ & 1.33 & 1.04 to 1.69 & 1.34 & 1.05 to 1.71 \\
\hline
\end{tabular}

Logistic regression was used for analysis.

NTD, New Taiwan Dollar; US\$1 $=$ NT\$30.

Literature has revealed that preterm births, a younger GA at birth and low birth weight are associated with childhood asthma. ${ }^{14} 23$ Tollanes et al reported that an association between birth by CS and increased risk of asthma was stronger for preterm children than for term children. Sonnenschein-van der Voort $e t a l^{23}$ further found that 'the association of lower birth weight with childhood asthma was largely explained by younger gestational age at birth'. Our results revealed that the association between GA at birth and children's asthma was attenuated after further controlling for parental history of asthma.

Our results also showed that there were no associations between preterm, late preterm or term at birth and childhood obesity. But childhood obesity was significantly associated with children born post-term before and after controlling for gestational diabetes mellitus and gestational weight gain.

\section{Association between neurodevelopmental disorders and CS delivery}

Our results do not support the association between CS and neurodevelopmental disorders in childhood after controlling for GA. GA at birth, especially preterm births, significantly influenced the association between CS births and neurodevelopmental disorders in childhood. This phenomenon is consistent with the viewpoint of Kapellou et $a l^{21}$ and Woythaler et $a .^{22}$
In addition to GA at birth, we also found that neurodevelopmental disorders occurred more in boys than in girls. However, recent literature has revealed that the increased risk of neurodevelopmental disorders in boys cannot exclude sex bias. ${ }^{24}{ }^{25}$ In this study, children with neurodevelopmental disorders were diagnosed and evaluated by paediatric psychiatrists and clinical psychologists, which might help to avoid the male bias.

Associations between maternal age and neurodevelopmental disorders in longitudinal or cohort studies are controversial. ${ }^{26}{ }^{27}$ Our study showed that a young maternal age at childbirth is a protective factor. Literature has shown that parental socioeconomic status such as low familial income is associated with an increased risk of neurodevelopmental disorders. ${ }^{28-30}$ We found that children who have a higher familial income have less risk for the occurrence of children's neurodevelopmental disorders compared with children with a lower familial income.

\section{Association between asthma and CS delivery}

A study in the UK in 2004 showed that an adjusted OR of delivery by CS is not associated with the subsequent development of physician-diagnosed asthma, wheezing or atopy in later childhood. ${ }^{15}$ Another population-based cohort study conducted by Juhn et al in the USA also revealed that mode of delivery is not associated with 
Table 3 Association between caesarean delivery and the occurrence of children's asthma after controlling for gestational age, children's and parental characteristics

\begin{tabular}{|c|c|c|c|c|c|c|}
\hline & Adjusted & & Adjusted & & Adjusted & \\
\hline & & $95 \% \mathrm{Cl}$ & & $95 \% \mathrm{Cl}$ & & $95 \% \mathrm{Cl}$ \\
\hline Caesarean delivery & 1.16 & 1.03 to 1.30 & 1.11 & 0.98 to 1.25 & 1.11 & 0.98 to 1.25 \\
\hline \multicolumn{7}{|l|}{ Gestational age (reference: $39-41$ weeks) } \\
\hline$<37$ weeks & & & 1.27 & 1.03 to 1.56 & 1.23 & 1.00 to 1.52 \\
\hline 37 weeks & & & 1.18 & 0.99 to 1.41 & 1.17 & 0.98 to 1.40 \\
\hline 38 weeks & & & 1.19 & 1.04 to 1.37 & 1.19 & 1.03 to 1.36 \\
\hline$\geqq 42$ weeks & & & 1.98 & 0.84 to 4.65 & 2.05 & 0.87 to 4.84 \\
\hline Gender, male & 1.40 & 1.25 to 1.57 & 1.39 & 1.24 to 1.56 & 1.40 & 1.24 to 1.57 \\
\hline First-born child & 1.23 & 1.09 to 1.38 & 1.26 & 1.12 to 1.42 & 1.27 & 1.13 to 1.44 \\
\hline \multicolumn{7}{|l|}{$\begin{array}{l}\text { Maternal age at birth of child (reference: } \\
\geqq 35 \text { years) }\end{array}$} \\
\hline$<25$ years & 0.90 & 0.71 to 1.15 & 0.90 & 0.71 to 1.15 & 0.88 & 0.69 to 1.12 \\
\hline 25-29 years & 1.14 & 0.95 to 1.36 & 1.14 & 0.96 to 1.36 & 1.13 & 0.94 to 1.34 \\
\hline 30-34 years & 1.03 & 0.88 to 1.22 & 1.04 & 0.88 to 1.23 & 1.02 & 0.87 to 1.21 \\
\hline \multicolumn{7}{|l|}{$\begin{array}{l}\text { Maternal education levels (reference: college } \\
\text { or above) }\end{array}$} \\
\hline$\leq$ Compulsoryschool & 0.67 & 0.53 to 0.85 & 0.67 & 0.53 to 0.85 & 0.68 & 0.54 to 0.86 \\
\hline Senior high school & 0.72 & 0.61 to 0.85 & 0.72 & 0.61 to 0.85 & 0.72 & 0.61 to 0.86 \\
\hline Junior college & 0.81 & 0.69 to 0.95 & 0.81 & 0.69 to 0.95 & 0.81 & 0.69 to 0.96 \\
\hline \multicolumn{7}{|l|}{$\begin{array}{l}\text { Family monthly income (NTD; } \\
\text { reference: }>100000)\end{array}$} \\
\hline$<30000$ & 0.67 & 0.52 to 0.86 & 0.66 & 0.52 to 0.85 & 0.67 & 0.53 to 0.86 \\
\hline $30000-100000$ & 0.87 & 0.74 to 1.02 & 0.87 & 0.74 to 1.02 & 0.88 & 0.75 to 1.04 \\
\hline Parental asthma history (reference: no) & & & & & 3.62 & 2.88 to 4.55 \\
\hline
\end{tabular}

Logistic regression was used for analysis.

NTD, New Taiwan Dollar; US\$1 NT\$30.

subsequent risk of developing childhood asthma or wheezing episodes after calculating their cumulative incidence rate and adjusting HRs. ${ }^{16}$ In this study, children's asthma was not significantly associated with CS births after further controlling for GA and parental history of asthma.

Kolokotroni et al reported that children with a family history of allergies enhance the positive association between CS delivery and asthma outcomes. ${ }^{12} \mathrm{Xu}$ et al revealed that maternal history of asthma (HR: 3.71) was strongly associated with offspring asthma. ${ }^{31}$ In our study, children born to a parent with a history of asthma was significantly associated with childhood asthma. However, Delbley et al found that CS births are associated with subsequent asthma hospitalisation only in premature and mothers with asthma have increased rates of CS and premature delivery. They noted that in addition to the hygiene hypothesis, factors including genetics, intrauterine environment and premature birth might also influence the association between birth by CS and childhood asthma. ${ }^{32}$

In this study, in addition to parental asthma history being significantly associated with child asthma, boys and first-born children were also positively associated with the occurrence of childhood asthma and maternal educational level was negatively associated with the occurrence of childhood asthma. Mersha et al showed that both genetic and gene expression data have sex-based differences in the genomic association with asthma. ${ }^{33} \mathrm{~A}$ significant association between first-born children and childhood asthma might be consistent with the hypothesis of 'in utero 'birth-order' T-cell programming' postulated by Kragh et al which does not support the hygiene hypothesis. Kragh et al revealed that first-born infants display a reduced anti-inflammatory profile in $\mathrm{T}$ cells at birth which may contribute to later development of immune-mediated diseases by increasing overall immune reactivity in first-born children compared with younger siblings. ${ }^{34}$ However, negative associations between maternal educational levels and childhood asthma are inconsistent with other studies. Renz-Polster et al did not find that maternal education levels influenced the occurrence of childhood asthma. ${ }^{35}$ Hermann et al reported that lower parental educational levels result in a higher prevalence of childhood asthma. ${ }^{36}$ 
Table 4 Association between caesarean delivery and the occurrence of children's obesity after controlling for gestational age, children's and parental characteristics

\begin{tabular}{|c|c|c|c|c|c|c|}
\hline & Adjusted & & Adjusted & & Adjusted & \\
\hline & & $95 \% \mathrm{Cl}$ & & $95 \% \mathrm{Cl}$ & & $95 \% \mathrm{Cl}$ \\
\hline Caesarean delivery & 1.15 & 1.06 to 1.26 & 1.15 & 1.05 to 1.25 & 1.13 & 1.04 to 1.24 \\
\hline \multicolumn{7}{|l|}{ Gestational age (reference: $39-41$ weeks) } \\
\hline$<37$ weeks & & & 1.03 & 0.89 to 1.20 & 1.04 & 0.90 to 1.21 \\
\hline 37 weeks & & & 1.04 & 0.91 to 1.18 & 1.04 & 0.91 to 1.18 \\
\hline 38 weeks & & & 1.00 & 0.90 to 1.10 & 1.00 & 0.90 to 1.10 \\
\hline$\geqq 42$ weeks & & & 2.28 & 1.26 to 4.13 & 2.29 & 1.26 to 4.15 \\
\hline Gender, male (reference: female) & 1.88 & 1.73 to 2.05 & 1.88 & 1.73 to 2.05 & 1.88 & 1.73 to 2.04 \\
\hline First-born child (ref: not first-born child) & 1.11 & 1.02 to 1.21 & 1.11 & 1.02 to 1.21 & 1.09 & 0.99 to 1.18 \\
\hline \multicolumn{7}{|l|}{$\begin{array}{l}\text { Maternal age at birth of child (reference: } \\
\geqq 35 \text { years) }\end{array}$} \\
\hline$<25$ years & 0.97 & 0.83 to 1.14 & 0.97 & 0.83 to 1.14 & 1.00 & 0.85 to 1.16 \\
\hline 25-29years & 0.99 & 0.87 to 1.12 & 0.99 & 0.87 to 1.12 & 1.00 & 0.88 to 1.13 \\
\hline 30-34 years & 0.91 & 0.81 to 1.03 & 0.91 & 0.81 to 1.03 & 0.92 & 0.82 to 1.04 \\
\hline \multicolumn{7}{|l|}{$\begin{array}{l}\text { Maternal education levels (reference: college or } \\
\text { above) }\end{array}$} \\
\hline$\leq$ Compulsory school & 1.70 & 1.44 to 2.00 & 1.69 & 1.43 to 2.00 & 1.71 & 1.45 to 2.02 \\
\hline Senior high school & 1.60 & 1.40 to 1.83 & 1.60 & 1.40 to 1.83 & 1.60 & 1.40 to 1.83 \\
\hline Junior college & 1.36 & 1.19 to 1.56 & 1.36 & 1.19 to 1.55 & 1.35 & 1.18 to 1.55 \\
\hline \multicolumn{7}{|l|}{$\begin{array}{l}\text { Family monthly income (NTD) } \\
\text { (reference: >100 000) }\end{array}$} \\
\hline$<30000$ & 1.04 & 0.88 to 1.24 & 1.04 & 0.87 to 1.23 & 1.05 & 0.89 to 1.25 \\
\hline $30000-100000$ & 1.06 & 0.93 to 1.21 & 1.06 & 0.93 to 1.21 & 1.07 & 0.94 to 1.22 \\
\hline Gestational diabetes mellitus (reference: no) & & & & & 1.53 & 1.20 to 1.95 \\
\hline \multicolumn{7}{|l|}{ Gestational weight gain (reference: $<11 \mathrm{~kg}$ ) } \\
\hline$\geqq 11 \mathrm{~kg}$ & & & & & 1.18 & 1.07 to 1.30 \\
\hline
\end{tabular}

Logistic regression was used for analysis.

NTD, New Taiwan Dollar US $\$ 1 \fallingdotseq N T \$ 30$.

\section{Association between childhood obesity and CS delivery}

The association between CS births and childhood obesity was robust after including GA, gestational diabetes and maternal gestational weight gain as potential predisposing factors. Our findings were consistent with the epidemiological study conducted by Huh $e a^{11}$ and a systematic review and meta-analysis by $\mathrm{Li}$ et al. ${ }^{17}$ However, Pei et al only found a greater likelihood of obesity at the age of 2 years in their CS group but not at the ages of 6 and 10 years in a prospective cohort study in Germany which was inconsistent with our results. ${ }^{37}$

In addition, boys, first-born children and lower maternal educational levels were also significantly associated with childhood obesity in the current study. Matthiessen et al reported that maternal educational level is inversely associated with childhood obesity, especially in boys. ${ }^{38}$ Fradkin et al found that children growing up with a high socioeconomic status are associated with a lower risk of childhood obesity but with variations across race/ ethnicity and gender. ${ }^{39}$
Literature reveals that children born to mothers with excessive gestational weight gain and gestational diabetes mellitus are associated with a higher risk of childhood obesity. ${ }^{40}{ }^{41}$ Our results also showed that children born to mothers with gestational diabetes mellitus and higher gestational weight gain have a higher risk of childhood obesity.

\section{Limitations of this study}

There are several limitations in this study. First, we did not evaluate relationships of childhood obesity and parental body mass index which is included in the TBCS. We used gestational weight gain as an associated factor instead of parental body mass index since parental body mass index may be influenced by other lifestyle habits. Second, indications for CS in this study were derived from self-reports by mothers or reports by primary caregivers, not from medical records. Some information such as maternal/fetal conditions that indicate CS or precise indications for CS that might be more related to these 
disorders were not evaluated. For example, whether there was a trial of labour before CS was not available. The infant might have exposed to some of the flora, even in the absence of vaginal delivery. Third, we looked at associations among these three disorders and modes of delivery as mutually exclusive, but we might have missed the possibility that these disorders might occur in combination. Lastly, we categorised any or in combination of learning disabilities, developmental delay, attention deficit hyperactivity disorder, sensory integration disorder or autism as neurodevelopmental disorders might distorted our outcomes interpretation because each of them might have different underlying risk factors.

\section{CONCLUSIONS}

Our results implied that CS birth was associated with the occurrence of children's neurodevelopmental disorders. However, children born before 38 weeks of GA by CS had significantly more children's neurodevelopmental disorders. CS birth was weakly associated with childhood asthma since parental asthma and preterm labour are stronger predisposing factors. The association between CS birth and childhood obesity is robust after controlling for related factors.

\section{Author affiliations \\ ${ }^{1}$ Institute of Health Policy and Management, College of Public Health, National Taiwan University, Taipei, Taiwan \\ ${ }^{2}$ Institute of Medicine, Chung Shan Medical University, Taichung, Taiwan \\ ${ }^{3}$ Department of Obstetrics and Gynecology, Chung Shan Medical University Hospital, Taichung, Taiwan \\ ${ }^{4}$ Department of Institute of Allied Health Sciences, National Cheng Kung University, Tainan, Taiwan \\ ${ }^{5}$ Department of Environmental and Occupational Medicine, National Taiwan University (NTU) College of Medicine and NTU Hospital, Taipei, Taiwan \\ ${ }^{6}$ Health Promotion Administration, Ministry of Health and Welfare, Taipei, Taiwan}

Acknowledgements We appreciate Dr Jeng-Dau Tsai from the Department of Pediatrics and Dr Vincent Chin-Hung Chen from the Department of Psychiatry at Chung Shan Medical University Hospital for kindly providing their expert opinion to help us interpret and classify our findings on neurodevelopmental disorders. We thank all the children and their parents who participated in this study, the interviewers who helped with data collection and all of the study groups who participated in the TBCS.

Contributors GC interpreted data, wrote drafts, revised the manuscript and approved the final manuscript as submitted. W-LC carried out the initial analyses, analysed research data and approved the final manuscript as submitted. B-CS, Y-LG and S-TC interpreted research data and approved the final manuscript as submitted. T-C conceptualised and designed the study, revised the initial manuscript and approved the final manuscript as submitted. All authors approved the final manuscript as submitted and agree to be accountable for all aspects of the work.

Funding Sponsored by the Health Promotion Administration, Department of Health and Welfare in Taiwan (D0H94\&HP\&1802, DOH95\&HP\&1802, DOH96\&HP\&1702, and DOH99\&HP\&1702).

Competing interests None declared.

Patient consent Obtained.

Ethics approval Institutional Review Board at National Taiwan University Hospital (No. 201604055RINC).

Provenance and peer review Not commissioned; externally peer reviewed.

Data sharing statement No additional data available.
Open Access This is an Open Access article distributed in accordance with the Creative Commons Attribution Non Commercial (CC BY-NC 4.0) license, which permits others to distribute, remix, adapt, build upon this work non-commercially, and license their derivative works on different terms, provided the original work is properly cited and the use is non-commercial. See: http://creativecommons.org/ licenses/by-nc/4.0/

(c) Article author(s) (or their employer(s) unless otherwise stated in the text of the article) 2017. All rights reserved. No commercial use is permitted unless otherwise expressly granted.

\section{REFERENCES}

1. Otamiri G, Berg G, Ledin T, et al. Delayed neurological adaptation in infants delivered by elective cesarean section and the relation to catecholamine levels. Early Hum Dev 1991;26:51-60.

2. Penders J, Thijs C, Vink C, et al. Factors influencing the composition of the intestinal microbiota in early infancy. Pediatrics 2006;118:511-21.

3. Dominguez-Bello MG, Costello EK, Contreras M, et al. Delivery mode shapes the acquisition and structure of the initial microbiota across multiple body habitats in newborns. Proc Natl Acad Sci U S A 2010;107:11971-5.

4. Kapellou O. Effect of caesarean section on brain maturation. Acta Paediatr 2011;100:1416-22.

5. Kostović I, Jovanov-Milosević N. The development of cerebral connections during the first 20-45 weeks' gestation. Semin Fetal Neonatal Med 2006;11:415-22.

6. Juárez I, Gratton A, Flores G. Ontogeny of altered dendritic morphology in the rat prefrontal cortex, hippocampus, and nucleus accumbens following Cesarean delivery and birth anoxia. J Comp Neurol 2008;507:1734-47.

7. Grönlund MM, Lehtonen OP, Eerola E, et al. Fecal microflora in healthy infants born by different methods of delivery: permanent changes in intestinal flora after cesarean delivery. $J$ Pediatr Gastroenterol Nutr 1999;28:19-25.

8. Collins SM, Surette M, Bercik P. The interplay between the intestinal microbiota and the brain. Nat Rev Microbiol 2012;10:735-42.

9. Thavagnanam S, Fleming J, Bromley A, et al. A meta-analysis of the association between Caesarean section and childhood asthma. Clin Exp Allergy 2008;38:629-33.

10. Ajslev TA, Andersen CS, Gamborg M, et al. Childhood overweight after establishment of the gut microbiota: the role of delivery mode, pre-pregnancy weight and early administration of antibiotics. Int $J$ Obes 2011;35:522-9.

11. Huh SY, Rifas-Shiman SL, Zera CA, et al. Delivery by caesarean section and risk of obesity in preschool age children: a prospective cohort study. Arch Dis Child 2012;97:610-6.

12. Kolokotroni O, Middleton N, Lamnisos D, et al. Asthma and atopy in children born by Cesarean section: effect modification based crosssectional study. BMC Pediatr 2012;12:179-88.

13. Cho CE, Norman M. Cesarean section and development of the immune system in the offspring. Am J Obstet Gynecol 2013;208:249-54.

14. Tollånes MC, Moster D, Daltveit AK, et al. Cesarean section and risk of severe childhood asthma: a population-based cohort study. $J$ Pediatr 2008;153:112-6.

15. Maitra A, Sherriff A, Strachan D, et al. Mode of delivery is not associated with asthma or atopy in childhood. Clin Exp Allergy 2004;34:1349-55.

16. Juhn YJ, Weaver A, Katusic S, et al. Mode of delivery at birth and development of asthma: a population-based cohort study. J Allergy Clin Immunol 2005;116:510-6.

17. Li HT, Zhou YB, Liu JM. The impact of cesarean section on offspring overweight and obesity: a systematic review and meta-analysis. Int $J$ Obes 2013;37:893-9.

18. Wen HJ, Chiang TL, Lin SJ, et al. Predicting risk for childhood asthma by pre-pregnancy, perinatal, and postnatal factors. Pediatr Allergy Immunol 2015;26:272-9.

19. American Psychiatric Association. DSM-5 overview: the future manual. http://www.dsm5.org/about/Pages/DSMVOverview.aspx (accessed 8 Apr 2016).

20. MacKay DF, Smith GC, Dobbie R, et al. Gestational age at delivery and special educational need: retrospective cohort study of 407,503 schoolchildren. PLoS Med 2010;7:e1000289.

21. Kapellou O, Counsell SJ, Kennea N, et al. Abnormal cortical development after premature birth shown by altered allometric scaling of brain growth. PLoS Med 2006;3:e265. 
22. Woythaler MA, McCormick MC, Smith VC. Late preterm infants have worse 24-month neurodevelopmental outcomes than term infants. Pediatrics 2011;127:e622-e629.

23. Sonnenschein-van der Voort AM, Arends LR, de Jongste JC, et al. Preterm birth, infant weight gain, and childhood asthma risk: a meta-analysis of 147,000 European children. J Allergy Clin Immunol 2014;133:1317-29.

24. Polyak A, Rosenfeld JA, Girirajan S. An assessment of sex bias in neurodevelopmental disorders. Genome Med 2015;7:94.

25. Sealey LA, Hughes BW, Pestaner JP, et al. Environmental factors may contribute to autism development and male bias: effects of fragrances on developing neurons. Environ Res 2015;142:731-8.

26. Lampi KM, Hinkka-Yli-Salomäki S, Lehti V, et al. Parental age and risk of autism spectrum disorders in a Finnish national birth cohort. $J$ Autism Dev Disord 2013;43:2526-35.

27. Tearne JE, Robinson M, Jacoby P, et al. Does late childbearing increase the risk for behavioural problems in children? A longitudinal cohort study. Paediatr Perinat Epidemiol 2015;29:41-9.

28. Rai D, Lewis $\mathrm{G}$, Lundberg $\mathrm{M}$, et al. Parental socioeconomic status and risk of offspring autism spectrum disorders in a Swedish population-based study. J Am Acad Child Adolesc Psychiatry 2012;51:467-76.

29. Martel MM. Individual differences in attention deficit hyperactivity disorder symptoms and associated executive dysfunction and traits: sex, ethnicity, and family income. Am J Orthopsychiatry 2013;83:165-75.

30. Russell G, Ford T, Rosenberg R, et al. The association of attention deficit hyperactivity disorder with socioeconomic disadvantage: alternative explanations and evidence. J Child Psychol Psychiatry 2014;55:436-45.
31. Xu R, DeMauro SB, Feng R. The impact of parental history on children's risk of asthma: a study based on the National Health and Nutrition Examination Survey-III. J Asthma Allergy 2015;8:51-61.

32. Debley JS, Smith JM, Redding GJ, et al. Childhood asthma hospitalization risk after cesarean delivery in former term and premature infants. Ann Allergy Asthma Immunol 2005;94:228-33.

33. Mersha TB, Martin LJ, Biagini Myers JM, Myers JMB, et al. Genomic architecture of asthma differs by sex. Genomics 2015;106:15-22.

34. Kragh M, Larsen JM, Thysen AH, et al. Divergent response profile in activated cord blood T cells from first-born child implies birth-orderassociated in utero immune programming. Allergy 2016;71:323-32.

35. Renz-Polster H, David MR, Buist AS, et al. Caesarean section delivery and the risk of allergic disorders in childhood. Clin Exp Allergy 2005;35:1466-72.

36. Hermann C, De Fine Olivarius N, Høst A, et al. Prevalence, severity and determinants of asthma in Danish five-year-olds. Acta Paediatr 2006;95:1182-90.

37. Pei Z, Heinrich J, Fuertes E, et al. Cesarean delivery and risk of childhood obesity. J Pediatr 2014;164:1068-73.

38. Matthiessen J, Stockmarr A, Fagt S, et al. Danish children born to parents with lower levels of education are more likely to become overweight. Acta Paediatr 2014;103:1083-8.

39. Fradkin $\mathrm{C}$, Wallander JL, Elliott MN, et al. Associations between socioeconomic status and obesity in diverse, young adolescents: variation across race/ethnicity and gender. Health Psychol 2015;34:1-9.

40. Lau EY, Liu J, Archer E, et al. Maternal weight gain in pregnancy and risk of obesity among offspring: a systematic review. J Obes 2014:2014:1-16.

41. Li H, Ye R, Pei L, et al. Caesarean delivery, caesarean delivery on maternal request and childhood overweight: a Chinese birth cohort study of 181380 children. Pediatr Obes 2014;9:10-16. 